\title{
General Anaesthesia versus Spinal Anaesthesia for Laparoscopic Cholecystectomy: Which Is Better Choice
}

\author{
Singh Vishwadeep ${ }^{1}$, Karki Geeta ${ }^{2}$, Mowar Ashita ${ }^{1}$, Singh Ankita ${ }^{3}$, Pahade Akhilesh ${ }^{4}$, Singh Lalit ${ }^{5}$ \\ ${ }^{1}$ Assistant Professor, Department of Anaesthesiology, Sri Ram Murti Smarak Institute of Medical sciences, Bareilly, India, ${ }^{2}$ Associate Professor, Department \\ of Anaesthesiology, Sri Ram Murti Smarak Institute of Medical sciences, Bareilly, India, ${ }^{3}$ Medical officer, District Hospital, Bareilly, India, ${ }^{4}$ Attending \\ Consultant, Department of Anaesthesiology, Rajiv Gandhi Cancer Institute, New Delhi, India, ${ }^{5}$ Professor and Head of Department of Pulmonary Medicine \\ and Crtitcal Care, Sri Ram Murti Smarak Institute of Medical sciences, Bareilly, India.
}

\section{Abstract}

Background: There is a growing evidence to suggest that regional anesthesia has an important role to play in the management of patients undergoing laparoscopic procedures. Subjects and Methods: We compared spinal anesthesia with general anesthesia, for laparoscopic cholecystectomy in 100 ASA grade 1 and 2 patients between the age of 18-50 years, divided equally into two groups given either GA or SA. The groups were compared by hemodynamic variables, intra operative events, post operative pain, operative conditions for surgeon and complications if any. Statistical Analysis: Data summarised as Mean \pm SE. Groups were compared by Student's t test , (ANOVA), NewmanKeuls post hoc test and chi-square $(\chi 2)$ test. Results: Hemodynamic comparison showed better hemodynamic profile in group SA than group GA. The time of rescue analgesia was comparatively higher in SA than GA. The no. of diclofenac used lower comparatively in SA than GA. Comparing the intra operative events of two groups there was higher shoulder pain in SA as compared to GA. However, hypotension was found similar between the two groups. Post operative side effects showed higher pruritis and urinary retention whereas lower sore throat in SA as compared to GA. However PONV and headache were found similar between the two groups. There was higher surgeon and patient satisfaction in GA as compared to SA. Conclusion: We concluded that laparoscopic cholecystectomy can be conducted safely under Spinal anaesthesia with excellent recovery and high degree of satisfaction in selected patients.

Keywords: Laparoscopy, General Anesthesia, Spinal anaesthesia, rescue analgesia, shoulder pain.

Corresponding Author: Dr. Geeta Karki, Associate Professor, Department of Anaesthesiology, Sri Ram Murti Smarak Institute of Medical sciences, Bareilly, India.

Received: February 2019

Accepted: March 2019

\section{Introduction}

The number of minimally invasive surgeries has increased exponentially over the last few decades because of less postoperative pain, decreased hospital stay, early resumption of routine activities and better cosmetic values . The most commonly used endoscope is the laparoscope and the surgical procedure is called laparoscopic surgery. ${ }^{[1]}$ Minimally invasive therapy is done with the general aim to minimize the trauma of Interventional process whilst still achieving satisfactory result. ${ }^{[2]}$

In laparoscopic surgery pneumoperitoneum, patient positioning, hemodynamic disturbances and ventilator problems like increased $\mathrm{PaCo} 2$ and gas embolism are the issues the anesthesiologist has to deal with. ${ }^{[1]}$

Laparoscopic cholecystectomy has become the treatment of choice for cholelithiasis because of its various advantages over open cholecystectomy such as minimal invasiveness, less postoperative pain, reduced hospital stay and early resumption of daily activities. ${ }^{[3,4]} \mathrm{We}$ need to relook on the popular assumption that general anesthesia is the only suitable technique for laparoscopic surgeries. Pressor response to endotracheal intubation, increased release of stress hormones, sore throat, post-operative pain, postoperative nausea and vomiting (PONV) are the disadvantages of using GA. There is a growing evidence to suggest that regional anesthesia has an important role to play in the management of patients undergoing laparoscopic procedures. The benefits of regional anesthetic techniques (Epidural, sub-arachnoid block) are avoidance of intubation, decreased need for sedatives and narcotics, better muscle relaxation and decreased surgical stress response, decreased post-operative pain and also cost effectiveness. ${ }^{[1]}$

In our study, we compared the efficacy of spinal anesthesia with general anesthesia, in laparoscopic cholecystectomy in healthy American Society of Anesthesiologists (ASA) grade 1 and 2 patients. Efficacy was compared by comparison of hemodynamic variables, any intraoperative event),operative condtions for surgeon, post operative pain and complications, if any.

\section{Subjects and Methods}

After approval from institute's ethical committee the prospective observational study was carried out in 100 
patients of ASA physical status 1 and 2 in age group 18-50 years, of either sex ,undergoing elective laparoscopic cholecysyectomy using spinal anesthesia or general anesthesia ,over a period of 6 months, after taking informed consent under medical ethics. The patients were randomly divided into two groups of 50 patients each.

The patients who were excluded from the study included those not giving consent, ASA Grade 3 and above, hypersensitivity to study drugs, pregnant females, emergency surgery, altered sensorium before induction, bleeding disorders, contraindications to pneumoperitoneum, contraindications to regional anaesthesia .

A sample size of 30 was arrived at according to the standard normal distribution theory and fixing type 1 error $(\alpha)$ at 0.05 and the power of study $(1 \beta)$ at 0.8 .

According to simple random sampling technique, out of all the cases that fulfilled the inclusion criteria , every even numbered case was allocated to Group GA and every odd numbered case was assigned to Group SA

All the patients were examined to assess their preoperative condition, demographic data and routine investigations which were recorded in brief. The patients were divided into two groups of 50 each: Group GA receiving general anaesthesia and group SA receiving spinal anaesthesia.

After taking the patients to the operating room, an intravenous line was secured in the right upper limb and infusion of $500 \mathrm{ml}$ of Ringer's Lactate solution was started.

Blood pressure cuff, ECG electrode and capnography monitors were applied. The initial pulse, blood pressure (BP), respiratory rate, ECG and end tidal $\mathrm{CO} 2(\mathrm{EtCO} 2)$ were noted.

For General anaesthesia ,all the patients were premedicated with Inj. Glycopyrrolate $4 \mathrm{mcg} / \mathrm{kg}$, Inj. Midazolam 0.02 $\mathrm{mg} / \mathrm{kg}$ and Inj. Ondensetron $0.08 \mathrm{mg} / \mathrm{kg}$ intravenously (i.v.) and Inj. Fentanyl $2 \mathrm{ug} / \mathrm{kg}$ i.v. Induction was done using Inj. Propofol $2 \mathrm{mg} / \mathrm{kg}$, and muscle relaxation was achieved by using Inj. Vecuronium $0.08 \mathrm{mg} / \mathrm{kg}$. Patients were intubated with adequate size endotracheal tube and for maintenance combination of O2, N20 and Isoflurane was used.

In patients randomized for spinal anaesthesia, the patients were first made to lie in supine position and all the monitors were attached. A 25-G Quincke spinal needle was introduced in subarachnoid space at L3-L4 interspace under all aseptic and antiseptic precautions in sitting position. After confirming free flow of cerebrospinal fluid, $3 \mathrm{ml}$ of hyperbaric Bupivacaine $0.5 \%$ plus $25 \mathrm{ug}$ of Fentanyl was injected intrathecally. Then, patient was made to lie supine and after keeping the patient in the 15o Trendelenberg position for 5 minutes, the patient was placed in a supine position. Approximately 10 minutes after intrathecal injection, the level of analgesia was checked.

During this period, $500 \mathrm{ml}$ of $0.9 \%$ Ringer's Lactate was infused. Level of block was assessed by segmental sensory (pin-prick) method. After achieving block level of $\mathrm{T} 4$, surgeon was asked to start surgery.

All the patients were monitored continuously both clinically and by noninvasive hemodynamic monitoring like electrocardiography, pulse, blood pressure, respiratory rate, pulse oxymetry and EtCO2 which were recorded at regular intervals. Any intra operative event such as shoulder pain, headache, nausea, vomiting and discomfort was recorded.
Time for demand of rescue analgesia by the patient was noted. Other postoperative events, either related to surgical or anaesthetic procedure, such as discomfort, nausea and vomiting, shoulder pain, urinary retention, pruritus, headache and other neurological sequelae, were recorded.

A questionnaire was filled by the surgeon immediately after surgery regarding surgical comfort. Questionnaire was also filled by the patient regarding intra operative and postoperative comfort and whether they would recommend the technique to their friends and relatives.

\section{Statistical analysis:}

Data was summarised as Mean \pm SE (standard error of the mean). Groups were compared by Student's t test. Groups were also compared by repeated measures two factor analysis of variance (ANOVA) using general linear models (GLM) and the significance of mean difference within (intra) and between the groups (inter) was done by Newman-Keuls post hoc test after adjusting for the multiple contrasts. Categorical (discrete) groups were compared by chi-square $(\chi 2)$ test. A two-tailed $(\alpha=2) \quad p<0.05$ was considered statistically significant. Analyses were performed on SPSS software (Windows version 17.0).

\section{Results}

The present study evaluates the effectiveness of spinal anaesthesia (SA) and general anaesthesia (GA) for laparoscopic cholecystectomy. Total 100 patients were recruited and randomized equally into two groups and given either GA $(\mathrm{GA}, \mathrm{n}=50)$ or $\mathrm{SA}(\mathrm{SA}, \mathrm{n}=50)$. The primary outcome measures of the study were hemodynamic parameters (PR, SBP and DBP), time of rescue analgesia and number (no.) of diclofenac ampoules used in $24 \mathrm{hrs}$. The secondary outcome measures of the study were intra operative events, post operative side effects, surgeon and patient satisfaction. The hemodynamic parameters were assessed at baseline, pre induction, post induction, post pneumoperitoneum, $15 \mathrm{~min}, 30 \mathrm{~min}, 45 \mathrm{~min}$ and $60 \mathrm{~min}$. The objective of the study was to compare the outcome measures between the two groups.

\section{Demographic characteristics}

The demographic characteristics (age, sex and weight) of two groups (GA and SA) at presentation is summarised in Table 1. The age of GA and SA ranged from 23-60 yrs and 20-67 yrs respectively with mean $( \pm$ SE) $44.04 \pm 1.51$ yrs and 43.18 \pm 1.72 yrs respectively. Similarly, the weight of GA and SA groups ranged from $53-83 \mathrm{~kg}$ and $44-86 \mathrm{~kg}$ respectively with mean $( \pm$ SE) $65.02 \pm 1.20 \mathrm{~kg}$ and $64.98 \pm 1.81 \mathrm{~kg}$ respectively. Comparing the mean age and weight of two groups, Student's t test showed similar age $(p=0.708)$ and weight $(\mathrm{p}=0.985)$ between the two groups i.e. did not differ significantly.

Further, in GA group, there were 31 (62.0\%) females and 19 $(38.0 \%)$ males whereas in SA group, it were $25(50.0 \%)$ and $25(50.0 \%)$ respectively. Comparing the sex proportion $(\mathrm{M} / \mathrm{F})$ of two groups, $\chi 2$ test showed similar sex proportions between the two groups $(\chi 2=1.46, \mathrm{p}=0.227)$ i.e. also not differ significantly.

The above comparisons concluded that subjects of two groups were demographically matched and thus comparable and hence may not influence the study outcome measures 
(primary and secondary).

\section{Primary outcome measures}

\section{Changes in hemodynamic parameters}

The pre and post hemodynamic parameters- pulse rate (PR), systolic blood pressure (SBP) and diastolic blood pressure (DBP), of two groups are shown in [Figure 1-3], respectively. In both groups, mean PR showed marked increase with time and the increase was evidently higher in GA than SA. The intra group comparisons showed significantly $(\mathrm{p}<0.001)$ higher mean $\mathrm{PR}$ from post induction to $15 \mathrm{~min}$ in both groups as compared to respective baseline. Further, in group GA, it lowered significantly $(\mathrm{p}<0.05$ or $\mathrm{p}<0.01$ ) at both 30 and $45 \mathrm{~min}$ as compared to baseline. The inter group comparison showed significantly $(\mathrm{p}<0.01$ or $\mathrm{p}<0.001$ ) different and lower mean PR at post induction, 15 and $30 \mathrm{~min}$ in SA as compared to GA. However, at other periods, it did not differ ( $p>0.05$ ) between the two groups i.e. found to be statistically the same.

In contrast, mean SBP in GA showed marked increase from pre induction to $15 \mathrm{~min}$ then decrease at 30 to $45 \mathrm{~min}$ and then increase at $60 \mathrm{~min}$ as compared to baseline. Whereas in $\mathrm{SA}$, it remained lower at all periods as compared to baseline except pre induction. Intra group comparison showed significantly $\quad(\mathrm{p}<0.001)$ higher mean SBP at pneumoperitoneum, 15 and $60 \mathrm{~min}$ as compared to baseline in GA. Whereas in SA, it lowered significantly $(\mathrm{p}<0.001)$ at pneumoperitoneum till end (60 min). Inter group comparison showed significantly $(\mathrm{p}<0.05$ or $\mathrm{p}<0.001)$ different and lower mean SBP at pneumoperitoneum, 15, 30 and $60 \mathrm{~min}$ in SA as compared to GA.

Similarly, mean DBP in GA remained higher at all periods as compared to baseline except pre induction and pneumoperitoneum whereas in SA, it was lower at all periods as compared to baseline. Intra group comparison showed significantly $(\mathrm{p}<0.001)$ lower mean DBP at pneumoperitoneum but significantly $(\mathrm{p}<0.001)$ higher at 60 min as compared to baseline in group GA. In contrast, in group SA, it was lower significantly $(\mathrm{p}<0.05$ or $\mathrm{p}<0.01$ or $\mathrm{p}<0.001)$ from pneumoperitoneum till end (60 $\mathrm{min})$ as compared to baseline. Inter group comparison showed significantly $(\mathrm{p}<0.01$ or $\mathrm{p}<0.001)$ different and lower mean DBP from 15 to $60 \mathrm{~min}$ in SA as compared to GA.

II. Time of rescue analgesia and no. of ampoules of diclofenac used

The time of rescue analgesia and number of diclofenac used of two groups is summarised in [Table 2] and also shown graphically in Fig.4 and 5, respectively. The time of rescue analgesia in GA and SA ranged from 10-60 min and 120$200 \mathrm{~min}$ respectively with mean $( \pm \mathrm{SE}) 34.10 \pm 1.89 \mathrm{~min}$ and $161.38 \pm 3.19$ min respectively. The time of rescue analgesia was comparatively higher in SA than GA. Comparing the mean time of rescue analgesia of two groups, Student's t test showed significantly different and higher $(78.9 \%)$ time of rescue analgesia in SA as compared to GA $(\mathrm{p}<0.001)$.

Similarly, the number of diclofenac used in GA and SA ranged from $0-2$ and $0-1$ respectively with mean $( \pm \mathrm{SE}) 0.72$ \pm 0.09 and $0.52 \pm 0.07$ respectively. The number of diclofenac used was lower comparatively in SA than GA. Comparing the mean no. of diclofenac used of two groups, Student's t test showed similar number of diclofenac used between the two groups $(\mathrm{p}=0.086)$ though it was lower $(27.8 \%)$ in SA as compared to GA.

\section{Secondary outcome measures}

\section{Intra operative events}

Intra operative events (shoulder pain, hypotension and bradycardia) of two groups is summarised in Table 3. Comparing the intra operative events of two groups, showed higher incidence of shoulder pain, in SA as compared to GA, ( $\mathrm{p}=$ 0.026). However, hypotension was found similar between the two groups $(\mathrm{p}=0.155)$ i.e. did not differ significantly.

Intra operative events of two groups were summarised in number (n) and percentage (\%) and compared by $\chi 2$ test.

\section{Table 1: Basic characteristics of two groups}

\begin{tabular}{|l|l|l|l|l|}
\hline Variable & $\begin{array}{l}\text { GA (n=50) } \\
(\boldsymbol{\%})\end{array}$ & $\begin{array}{l}\text { SA (n=50) } \\
(\boldsymbol{\%})\end{array}$ & $\begin{array}{l}\text { t/ } \mathbf{\chi 2} \\
\text { value }\end{array}$ & P value \\
\hline Age $(\mathrm{yrs})$ & $44.04 \pm 1.51$ & $43.18 \pm 1.72$ & 0.38 & 0.708 \\
\hline $\begin{array}{l}\text { Sex: } \\
\begin{array}{l}\text { Female } \\
\text { Male }\end{array}\end{array}$ & $\begin{array}{l}31(62.0) \\
19(38.0)\end{array}$ & $\begin{array}{l}25(50.0) \\
25(50.0)\end{array}$ & 1.46 & 0.227 \\
\hline Weight $(\mathrm{kg})$ & $65.02 \pm 1.20$ & $64.98 \pm 1.81$ & 0.02 & 0.985 \\
\hline
\end{tabular}

Age and weight of two groups were summarised in Mean \pm SE and compared by Student's $\mathrm{t}$ test whereas sex was summarised in number $(\mathrm{n})$ and percentage $(\%)$ and compared by $\chi 2$ test.

Table 2: Time of rescue analgesia and no. of diclofenac used of two groups

\begin{tabular}{|l|l|l|l|l|}
\hline Variable & $\begin{array}{l}\text { GA } \\
(\mathbf{n = 5 0})\end{array}$ & $\begin{array}{l}\text { SA } \\
(\mathbf{n = 5 0 )}\end{array}$ & $\begin{array}{l}\mathbf{t} \\
\text { value }\end{array}$ & $\begin{array}{l}\text { P } \\
\text { value }\end{array}$ \\
\hline $\begin{array}{l}\text { Time of rescue analgesia } \\
\text { (min) }\end{array}$ & $\begin{array}{l}94.10 \pm \\
1.89\end{array}$ & $\begin{array}{l}161.38 \quad \pm \\
3.19\end{array}$ & 34.32 & $<0.001$ \\
\hline Diclofenac (no.) & $0.72 \pm 0.09$ & $0.52+0.07$ & 1.74 & 0.086 \\
\hline
\end{tabular}

Time of rescue analgesia and no. of diclofenac used of two groups were summarised in Mean \pm SE and compared by Student's t test.

Table 3: Distribution of intra operative events of two groups

\begin{tabular}{|c|c|c|c|}
\hline Variable & $\begin{array}{l}\text { GA } \\
(n=50)(\%)\end{array}$ & $\begin{array}{l}\text { SA } \\
(\mathrm{n}=50)(\%)\end{array}$ & $\begin{array}{l}P \\
\text { value }\end{array}$ \\
\hline $\begin{array}{l}\text { Shoulder } \\
\text { pain: } \\
\text { No } \\
\text { Yes }\end{array}$ & $\begin{array}{l}50(100.0) \\
0(0.0)\end{array}$ & $\begin{array}{l}12(24.0) \\
38(76.0)\end{array}$ & 0.026 \\
\hline $\begin{array}{l}\text { Hypotension: } \\
\text { No } \\
\text { Yes }\end{array}$ & $\begin{array}{l}33(66.0) \\
17(34.0) \\
\end{array}$ & $\begin{array}{l}26(52.0) \\
24(48.0) \\
\end{array}$ & 0.155 \\
\hline $\begin{array}{l}\text { Bradycardia } \\
\text { No } \\
\text { Yes } \\
\end{array}$ & $\begin{array}{r}44(88.0) \\
6(12.0) \\
\end{array}$ & $\begin{array}{l}40(80.0) \\
10(20.0)\end{array}$ & 0.529 \\
\hline
\end{tabular}

Table 4: Distribution of post operative side effects of two groups

\begin{tabular}{|l|l|l|l|}
\hline Variable & $\begin{array}{l}\text { GA } \\
(\mathbf{n = 5 0}) \mathbf{( \% )}\end{array}$ & $\begin{array}{l}\text { SA } \\
(\mathbf{n = 5 0}) \mathbf{( \% )}\end{array}$ & $\begin{array}{l}\text { P } \\
\text { Value }\end{array}$ \\
\hline $\begin{array}{l}\text { PONV: } \\
\text { No } \\
\text { Yes }\end{array}$ & $30(60.0)$ & $\begin{array}{l}4(84.0) \\
8(16.0)\end{array}$ & 0.080 \\
\hline $\begin{array}{l}\text { Headache: } \\
\text { No } \\
\text { Yes }\end{array}$ & $\begin{array}{l}40(40.0) \\
5(10.0)\end{array}$ & $\begin{array}{l}43(86.0) \\
7(14.0)\end{array}$ & 0.656 \\
\hline $\begin{array}{l}\text { Pruritus: } \\
\text { No } \\
\text { Yes }\end{array}$ & $\begin{array}{l} \\
6(12.0)\end{array}$ & $\begin{array}{l}21(42.0) \\
29(58.0)\end{array}$ & $<0.001$ \\
\hline $\begin{array}{l}\text { Urinary retention: } \\
\text { No }\end{array}$ & $\begin{array}{l}50(100.0) \\
\text { Yes }\end{array}$ & $\begin{array}{l}32(64.0) \\
18(36.0)\end{array}$ & $<0.001$ \\
\hline $\begin{array}{l}\text { Sore throat: } \\
\text { No } \\
\text { Yes }\end{array}$ & $18(36.0)$ & $\begin{array}{l}50(100.0) \\
0(0.0)\end{array}$ & $<0.001$ \\
\hline
\end{tabular}

PONV: post operative nausea and vomiting. Post operative side effects of two groups were summarised in number $(\mathrm{n})$ and percentage $(\%)$ and compared by $\chi 2$ test. 


\section{Post operative side effects}

Post operative side effects (PONV, headache, pruritis, hypotension, urinary retention, sore throat and bradycardia) of two groups is summarised in Table 4. Comparing the post operative side effects of two groups, $\chi 2$ test showed significantly higher pruritus $(\mathrm{p}<0.001)$ and urinary retention $(\mathrm{p}<0.001)$ in SA as compared to GA. However, PONV ( $\mathrm{p}=0.080)$ and sore throat $(\mathrm{p}<0.001)$ were higher in GA as compared to SA. Incidence of headache $(\mathrm{p}=0.656)$, and was found similar between the two groups i.e. did not differ significantly.

\section{Surgeon and patient satisfaction}

Lastly, the surgeon and patient satisfaction (excellent/very good/ Not good) of two groups is summarised in Table 5. Comparing the surgeon and patient satisfaction of two groups, $\chi 2$ test showed higher surgeon (excellent + very good: $90 \%$ vs. $84 \%, \mathrm{p}=0.075$ ) and patient (excellent + very good: $90 \%$ vs. $82 \%, \mathrm{p}=0.084$ ) satisfaction in GA as compared to SA but it was not statistically significant.

Table 5: Distribution of surgeon and patient satisfaction of two groups

\begin{tabular}{|l|l|l|l|}
\hline Variable & $\begin{array}{l}\text { GA } \\
(\mathbf{n = 5 0})(\boldsymbol{\%})\end{array}$ & $\begin{array}{l}\text { SA } \\
(\mathbf{n = 5 0})(\boldsymbol{\%})\end{array}$ & $\begin{array}{l}\text { P } \\
\text { Value }\end{array}$ \\
\hline Surgeon satisfaction: & $23(46.0)$ & $14(28.0)$ & 0.075 \\
Excellent & $22(44.0)$ & $28(56.0)$ & \\
Good & $5(10.0)$ & $8(16.0)$ & \\
Not Good & $26(52.0)$ & $19(38.0)$ & 0.084 \\
\hline Patient satisfaction: & $18(36.0)$ & $22(44.0)$ & \\
Excellent & $5(10.0)$ & $9(18.0)$ & \\
Good & Not Good & \\
\hline
\end{tabular}

Surgeon and patient satisfaction of two groups were summarised in number (n) and percentage (\%) and compared by $\chi 2$ test.

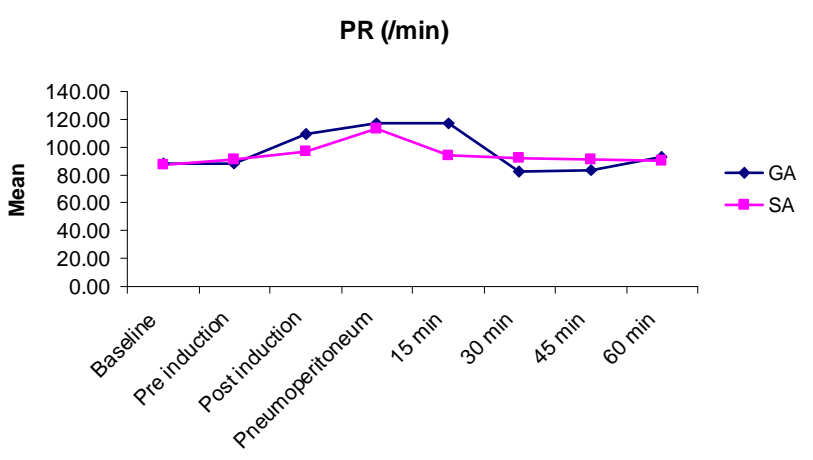

Figure 1: Mean PR of two groups over the periods.

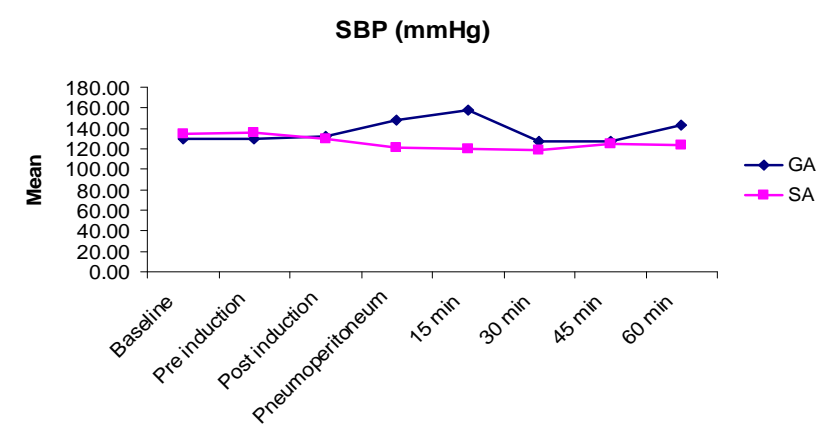

Figure 2: Mean SBP of two groups over the periods.

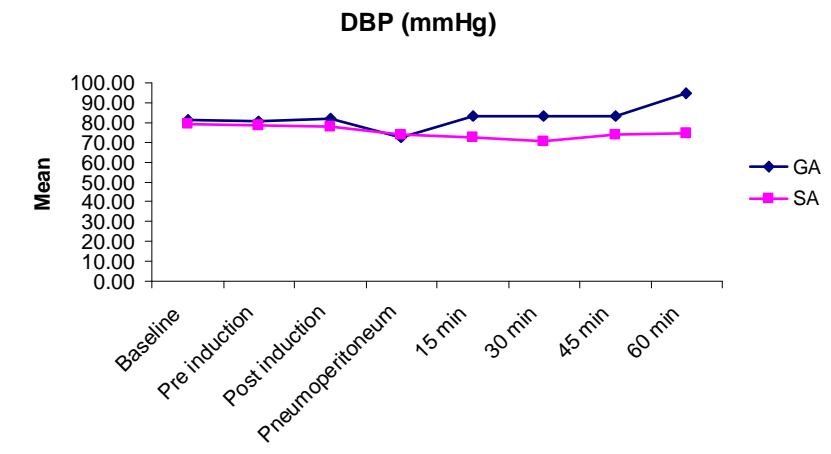

Figure 3: Mean DBP of two groups over the periods.

Time of rescue analgesia $(\min )$

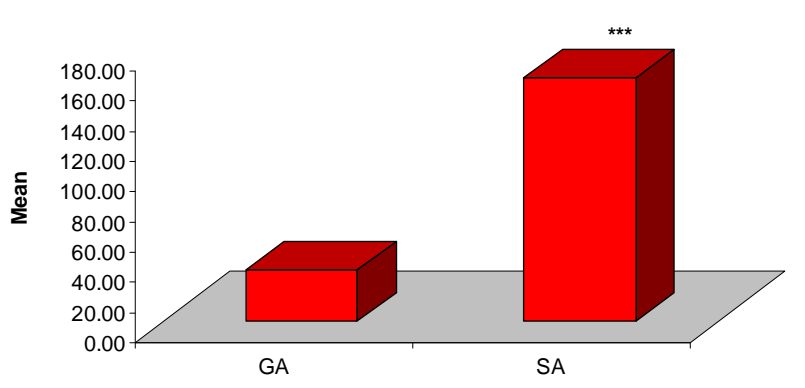

Figure 4: Comparison of mean time of rescue analgesia of two groups.

**** $<0.001$ - as compared to GA

Number of diclofenac used

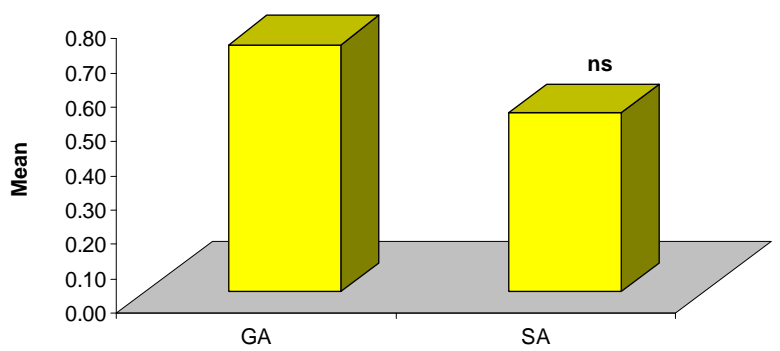

Figure 5: Comparison of mean number of ampoules of diclofenac used of two groups.

nsp $>0.05$ - as compared to GA

\section{Discussion}

General anaesthesia has remained the most accepted modality of anaesthesia for laparoscopic cholecystectomy as it provides analgesia, unconsciousness and relaxation and better airway control. ${ }^{[1]}$ Many recent studies have also demonstrated the benefits of regional anaesthesia in patients undergoing laparoscopic cholecystectomy which include reduction of stress response to surgery, avoidance of airway instrumentation, good muscle relaxation, excellent intraoperative and postoperative analgesic efficacy and lower incidence of deep vein thrombosis. ${ }^{[5]}$

Spinal anaesthesia is less invasive technique with lower morbidity and mortality as compared to general anaesthesia. 
In spinal anaesthesia the patient is awake, has less pain in immediate postoperative period due to persistent neurological blockade, absence of side effects like PONV, sore throat and pain related to intubation and extubation associated with general anaesthesia. Patients who receive spinal anaesthesia tend to ambulate earlier than patients with GA. ${ }^{[6]}$

The present study was conducted in ASA I and II patients scheduled to undergo laparoscopic cholecystectomy. Total 100 patients were recruited and randomized equally into two groups given either GA $(n=50)$ or $\mathrm{SA}(\mathrm{n}=50)$.

The subjects of two groups were demographically matched and were comparable as summarised in [Table 1].

In the hemodynamic parameters ( $\mathrm{PR}, \mathrm{SBP}$ and $\mathrm{DBP})$ there was a significant increase in pulse rate( $P R)$ from post induction and to $15 \mathrm{~min}$ in both groups as compared to respective baseline. In both groups, mean PR showed marked increase with time and the increase was evidently higher in GA than SA. Similar results have been found in the study done by Gurudatta KN et all. The inter group comparison showed significantly $(\mathrm{p}<0.01$ or $\mathrm{p}<0.001)$ different and lower mean PR at post induction, 15 and $30 \mathrm{~min}$ in SA as compared to GA. In GA group, the increase in pulse rate initially is due to the mechanical and neurohumoral effects of $\mathrm{CO} 2$ insufflation. The increase in PR was less in group SA as the increase in PR due to peritoneal insufflation was counteracted by the decrease in PR caused by sympatholytic effect of spinal anaesthesia.

Inter group comparison showed significantly $(\mathrm{p}<0.05$ or $\mathrm{p}<0.001)$ lower mean SBP at different periods in SA as compared to GA. Similarly, mean DBP in GA remain higher from baseline value at all periods as compared to SA. Inter group comparison showed significantly $(p<0.01$ or $p<0.001)$ lower mean DBP in SA as compared to GA. The lower SBP and DBP is attributed to the sympatholytic effect of spinal anaesthesia.

Similar results have been found in Mehanna et al, ${ }^{[7]}$ and Mehta et al, ${ }^{[2]}$ and Sale et al, ${ }^{[8]}$ in which there was highly statistically significant increase in mean arterial blood pressure in GA as compared to SA.

Intra operative events (shoulder pain, hypotension, nausea, vomiting) of two groups as summarised in [Table 4], show a higher incidence of shoulder pain, nausea and vomiting in SA as compared to GA. However, incidence of hypotension was found similar between the two groups $(p=0.155)$ i.e. did not differ significantly. Severe right shoulder pain is one of the major intraoperative problem in laparoscopic cholecystectomy. ${ }^{[9]}$ Pain in right shoulder is attributed to irritation of diaphragm by $\mathrm{CO} 2$ pneumoperitoneum. In our study it was found in 12 patients but only 4 patients had to be given fentanyl $25 \mathrm{mcg}$ while rest of the patients were managed by non pharmacological methods like reassurance, shoulder massage, decreasing intra-abdominal pressure and limited tilting of table. There was no need of conversion to GA in any case.

Similar incidence of pain/discomfort in right shoulder in the spinal group was also noted in a study conducted by Mehta et al, ${ }^{[2]}(23 \%)$, Gurudatta K N et al, ${ }^{[1]}(24 \%)$, Van Zandart AAJ et al, ${ }^{[10]}(25 \%)$ and Arati S et al, ${ }^{[11]}(18 \%)$. However, study done by Tzovaras $\mathrm{G}$ et al, ${ }^{[12]}$ reported an incidence of $43 \%$ which is much higher than that in our study. Lower incidence of shoulder pain in our study may be due to intrathecal fentanyl.

Among post operative side effects, it was seen that higher incidence of pruritus $(12.0 \%$ vs. $58.0 \%)$ and urinary retention $(0.0 \%$ vs. $36.0 \%)$ occured in SA as compared to GA whereas higher incidence of sore throat $(64.0 \%$ vs. $0.0 \%$ ) occured in GA as compared to SA. Pruritus in spinal group is due to the opioid (fentanyl) used .

Post operative nausea and vomiting is a common problem after laparoscopic cholecystectomy under GA.13 In our study, Group GA had $40 \%(n=20)$ patients with PONV while group SA had $16 \%(\mathrm{n}=8)$ patients with PONV and it was statistically non significant $(\mathrm{p}=0.080)$.

Pain is a common problem in postoperative period. In our study, time for rescue analgesia in SA group was $161.38 \pm$ 3.19 minutes and in GA group it was $94.10 \pm 1.89$ minutes ( $\mathrm{p}<0.001)$. It was managed by injection Diclofenac $75 \mathrm{mg}$ slow iv. Prolonged duration of analgesia in spinal anaesthesia was also found in studies of Sinha R et al, ${ }^{[14]}$ and Bessa S S et al. ${ }^{[15]}$ As shown in [Table 3], the time of rescue analgesia was comparatively higher in SA than GA. $(p<0.001)$ and the mean number of ampoules of diclofenac used in $24 \mathrm{hrs}$ was lower in SA than GA though not statistically significant.

There were similar findings in a study conducted by Mehanna et $\mathrm{al}^{\left[{ }^{[7]}\right.}$ in which the mean number of analgesic ampoules needed was significantly lower in SA group $0.6 \pm$ 0.29 ampoules/patient as compared to $1.6 \pm 0.5$ ampoules /patient in GA group.

Similar results were found with Mehta et al, ${ }^{[2]}$ while comparing both the groups, which suggested that SA group had better analgesia than that of GA group.

In answer to the questionnaire regarding abdominal relaxation and intaoperative surgical comfort, surgeons were satisfied with the technique in majority of cases. In GA group, in 5 cases the surgeon complained about inadequate relaxation where additional top up dose of muscle relaxant had to be given. In SA group, in 6 cases the surgeon was not comfortable because of patient moving shoulder because of pain and in 3 cases abdominal relaxation was not adequate. This problem was overcome by giving fentanyl $25 \mathrm{mcg}$ and propofol $30 \mathrm{mg}$ intravenously respectively. They stated that there was no significant difference in abdominal relaxation and surgical comfort in spinal anaesthesia and general anaesthesia. Similar results were found in studies by Arati S et al, ${ }^{[11]}$ Yusek Y N et al, ${ }^{[6]}$ and Prasad C G S et al. ${ }^{[16]}$

In answer to the questionnaire regarding the comfort during the procedure and postoperative period, majority of patients were satisfied and would recommend the technique to their relatives and friends.

\section{Conclusion}

The results of our study encourage us to conclude that laparoscopic cholecystectomy can be conducted safely and with excellent recovery and high degree of satisfaction in selected patients. Our study was conducted in ASA 1 and 2 patients, may be further studies are required with a broader spectrum of patients. Spinal anaesthesia appears to be safer and better alternative in patients where GA is contraindicated. However, this technique requires cooperative patients, a skilled surgeon with gentle technique 
and enthusiastic anaesthesiologist. Spinal anaesthesia provides pain free post-operative period and smooth recovery with minimal post-operative sequelae.

\section{Acknowledgement}

I am thankful to Director, Institute for Data Computing and Training (I.D.C.T), Lucknow for providing valuable assistance in data analysis.

\section{References}

1. Gurudatta KN, Mohammed Arif. A clinical study of comparison between general anaesthesia and spinal anaesthesia for lower abdominal laparoscopic surgeries. Scholars Journal of Applied Medical Sciences. 2014; 2(3D):1127-33.

2. Purvi J Mehta, Hiral R Chavda, Ankit P Wadhwana, Mehul M Porecha. Comparative analysis of Spinal versus general anesthesia for laparoscopic cholecystectomy : A controlled, prospective, randomized trial. Anesthesia: Essays and Researches.

3. Grace PA, Qureshi A, Coleman J et al. Reduced postoperative hospitalization after laparoscopic cholecystectomy. British Journal of Surgery. 1991;78,160.

4. Kere RL, Lurie N, Borsal C et al. The outcomes of elective laparoscopic and open cholecystectomies. J Am Coll Surg.1995;180-86.

5. Kalaivani V, Vinayak S Pujari, Sreevastha M R, Bharti V Hiremath and Yatish Bevinaguddaiah. Laparoscopic Cholecystectomy: Spinal Anaesthesia vs. General Anaesthesia: A prospective randomized study. Journal of Clinical and Diagnostic Research. 2014 Aug, Vol-8(8): NC01-NC04

6. Yunus Nadi Yuksek, Arif Zeki Akat, Ugur Gozalan et al. Laparoscopic Cholecystectomy under Spinal Anaesthesia. American J
Anaesthesiology. 2008;195;533-36.

7. Mehanna AM, Ibrahim AG (2017) Comparative Study between General and Spinal Anaesthesia in Laparoscopic Appendectomy. J Anesth Clin Res 8: 713.

8. Sale HK, Shendage VJ, Wani S. Comparative Study between General Anesthesia and Combined General Anesthesia with Spinal Anesthesia in Laparoscopic Cholecystectomy. Int J Sci Stud 2016;3(11):157-162.

9. Gadacz TR , Talamini MA , Lillemoe KD et al. Laparoscopic cholecystectomy. Surg Clin North Am $1990 ; 70: 1249-62$.

10. Zundert AA V, Stultiens G, Jakimowicz JJ, et al. Laparoscopic cholecystectomy under segmental thoracic spinal anaesthesia: a feasibility study.Br J Anaesth 2007;98:682-6.

11. Srivastava Arati, Niranjan Ashutosh. Comparative analysis of spinal vs general anaesthesia for laparoscopic cholecystectomy: A prospective randomized study. The Internet Journal of Anaesthesiology. 2010;24 (1).

12. Tzovaras G, Fafoulakis F, Prtsas K et al. Spinal vs General Anaesthesia for laparoscopic cholecystectomy: interim analysis of a controlled randomized trial. Arch Surg.2008;143(5):497-501.

13. So JBY, Cheong KF, Sng C et al. Ondansetron in the prevention of postoperative nausea and vomiting after laparoscopic cholecystectomy. Surg Endosc 2002; 286 - 8.

14. Rajeev Sinha , A K Guruwara , S C Gupta. Laparoscopic cholecystectomy under spinal anaesthesia: A study of 3492 patients. Journal of Laparoscopic \& Advanced Surgical Techniques. 2009;19(3);323-26.

15. Sameer S Bessa, Islam A, El Sayes, et al. Laparoscopic cholecystectomy under spinal versus general anaesthesia : A prospective randomized study. Journal of Laparoendoscopic \& Advanced Surgical Techniques.2010;20(6);515-18.

16. Prasad C G S, Prashant P, Mannur, Suresh G. Spinal Anaesthesia versus General Anaesthesia for Laparoscopic Cholecystectomy - A prospective randomized controlled study.

Copyright: ( ) the author(s), publisher. Academia Anesthesiologica International is an Official Publication of "Society for Health Care \& Research Development". It is an open-access article distributed under the terms of the Creative Commons Attribution Non-Commercial License, which permits unrestricted non-commercial use, distribution, and reproduction in any medium, provided the original work is properly cited.

How to cite this article: Singh V, Karki G, Mowar A, Singh A, Pahade A, Singh L. General Anaesthesia versus Spinal Anaesthesia for Laparoscopic Cholecystectomy: Which Is Better Choice. Acad. Anesthesiol. Int. 2019;4(1):61-66.

DOI: dx.doi.org/10.21276/aan.2019.4.1.14

Source of Support: Nil, Conflict of Interest: None declared. 